\title{
Erratum to: Trauma team utilization of universal precautions: if you see something, say something
}

T. Peponis ${ }^{1}$ - M. C. Cropano $^{1}$ - A. Larentzakis ${ }^{1}$ - G. M. van der Wilden ${ }^{1}$. Y. A. Mejaddam ${ }^{1}$ C. A. Sideris ${ }^{1}$ M. Michailidou ${ }^{1} \cdot$ K. Fikry ${ }^{1}$ A. Bramos ${ }^{1}$. S. Janjua ${ }^{1} \cdot$ Y. Chang ${ }^{1} \cdot$ D. R. King ${ }^{1}$

Published online: 3 December 2016

(C) Springer-Verlag Berlin Heidelberg 2016

\section{Erratum to: Eur J Trauma Emerg Surg DOI 10.1007/s00068-016-0663-8}

The original version of this article unfortunately contained a mistake.

The spelling of the G. M. van der Wildens' name was incorrect.

The online version of the original article can be found under doi:10.1007/s00068-016-0663-8.

\footnotetext{
D. R. King

DKING3@PARTNERS.ORG

Division of Trauma, Emergency Surgery, and Surgical Critical Care, Massachusetts General Hospital \& Harvard Medical School, 165 Cambridge Street, Suite 810, Boston, MA 02114, USA
} 